\title{
Longitudinal analysis of the effect of academic failure tolerance on academic achievement fluctuation in medical school students
}

\author{
Su Jin Chae ${ }^{1,2}$, Miran Kim ${ }^{1,3}$ and Ki Hong Chang ${ }^{1}$ \\ ${ }^{1}$ Office of Medical Education, Departments of ${ }^{2}$ Medical Humanities \& Social Medicine and ${ }^{3}$ Obstetrics \& Gynecology, \\ Ajou University School of Medicine, Suwon, Korea
}

Purpose: Academic failure tolerance (AFT) is one of the important psychological concepts in education, but its applications in medical education are rare. Thus, the purpose of this study was to investigate the effect of academic failure tolerance on academic achievement fluctuation among medical school students using a longitudinal research design.

Methods: The subjects were 43 medical students who responded to the AFT test. This study analyzed the longitudinal data of achievement scores up to the 2nd academic year (2012-2013) among students who were divided into academic achievement improvement and decline groups.

Results: Comparing the improvement and decline groups' mean academic achievement fluctuation scores demonstrated that behavior and preferred task difficulty showed high scores whereas feeling scores were lower in the improvement group $(p<0.05)$.

Conclusion: In the improvement group, despite the higher negative feeling scores during academic failure, the students favored the more difficult subjects and were more assiduous in their studies. This will form an important basis for enhancing academic achievement among medical students.

Key Words: Academic failure tolerance, Motivation, Educational status

\section{Introduction}

Academic failure tolerance (AFT) is one of the important psychological concepts in education, but its applications in medical education are rare [1]. Opinions regarding the relationship between academic failure experience and subsequent academic activities have varied from negative to positive among various authors [2]. Early researchers who held the negative opinion theorized about learned helplessness, in which if a student experiences repeated failure to control his or her environment, then he or she will learn that controlling the environment control is impossible, which will result in the failure to pursue academic activity and in decreased academic motivation [3]. In contrast, authors who hold the positive opinion suggest the constructive failure theory, in which experience of failure affords and promotes positive, constructive thought processes for students under certain conditions [4]. In later years, investigators defined AFT as a result of the positive aspect of constructive failure [5].
Received: September 18, 2015 • Revised: November 30, 2015 • Accepted: December 8, 2015 Corresponding Author: Miran Kim (http://orcid.org/0000-0001-5553-5334)

Department of Obstetrics \& Gynecology, Ajou University School of Medicine, 206 World cup-ro, Yeongtong-gu, Suwon 16499, Korea

Tel: +82.31.219.5300 Fax: +82.31.219.5245 email: kmr5300@ajou.ac.kr
Korean J Med Educ 2016 Mar; 28(1): 25-28.

http://dx.doi.org/10.3946/kjme.2016.6

eISSN: 2005-7288

(C) The Korean Society of Medical Education. All rights reserved. This is an open-access article distributed under the terms of the Creative Commons Attribution Non-Commercial License (http:// creativecommons.org/licenses/by-nc/3.0/), which permits unrestricted non-commercial use, distribution, and reproduction in any medium, provided the original work is properly cited. 
AFT includes the feelings that an individual $\mathrm{ex}^{-}$ periences after personal academic failure, and it also entails the tendency to establish a plan and to formulate measures for recovery from failure, both activities that attempt to correct for the failure and preferred task difficulty, which entails selecting difficult subjects in spite of the possibility of academic failure $[6,7]$.

In the present research, the authors focus to evaluate the attitudes and lives of medical students after they have experienced academic failure despite endless challenges and assessments. The purpose of this study was to investigate the effect of AFT on the fluctuations in academic achievement among medical school students using a longitudinal research design.

\section{Subjects and methods}

\section{Subjects}

The subjects of this study are 43 students in Ajou University School of Medicine. This study was conducted longitudinally for 2 years 2012-2013. The subjects are divided into two groups, improvement group and decline group. The subjects were divided into two groups: the improvement group showed improved academic grades from 2012 to 2013 ( $\mathrm{n}=28$ ), and the decline group showed grade declines during the same period $(n=15)$.

\section{Academic failure tolerance test}

AFT was measured using the academic failure tolerance test [8]. This instrument is composed of 18 items divided into three subscales of six items each (Table 1). Responses were recorded on a 6-point Likert scale and the higher the test scores, the higher the AFT. The subscales assess three factors of failure tolerance (feeling, behavior, preferred task difficulty).
Table 1. Reliability of the Academic Failure Tolerance Subscale

\begin{tabular}{lcc}
\hline \multicolumn{1}{c}{ Subscale } & No. of items & Cronbach $\alpha$ \\
\hline Feeling & 6 & 0.82 \\
Behavior & 6 & 0.77 \\
Preferred task difficulty & 6 & 0.87 \\
\hline
\end{tabular}

The factors of "failure tolerance" have the following characteristics. The feeling factor represents the individual's positive or negative emotional responses after experiencing academic failure. The behavior factor represents how an individual behaves, and the preferred task difficulty factor refers to an individual's cognitive and behavioral attitudes towards a task's difficulty. This suggests that despite a high probability of failure, there is a higher likelihood of AFT among students who select difficult subjects.

\section{Statistical analysis}

According to the groups as divided (improvement group, decline group), differences among factors of "failure tolerance" (feeling, behavior, preferred task difficulty) were studied. The differences between the improvement and decline groups were analyzed with a one-way analysis of variance.

\section{Results}

The differences between the improvement and decline groups are shown in Table 2. We observed significant differences with respect to feelings and behaviors between the two groups $(\mathrm{p}<0.05)$. The improvement group demonstrated higher scores compared with the decline group in behavior (3.64 vs. 2.84) and preferred task difficulty (3.46 vs. 3.19) but showed lower scores for feelings (3.08 vs. 3.80). 
Table 2. Academic Failure Tolerance Score Differences according to Fluctuations in Academic Achievement

\begin{tabular}{llll}
\hline \multicolumn{1}{c}{ Factor } & \multicolumn{1}{c}{ Group (n) } & Mean \pm SD & p-value \\
\hline Feeling & Improvement group (28) & $3.08 \pm 0.60$ & $0.014^{*}$ \\
& Decline group (15) & $3.80 \pm 0.43$ & \\
Behavior & Improvement group (28) & $3.64 \pm 0.72$ & $0.038^{*}$ \\
\multirow{2}{*}{ Preferred task difficulty } & Decline group (15) & $2.84 \pm 0.85$ & \\
& Improvement group (28) & $3.46 \pm 0.63$ & 0.371 \\
& Decline group (15) & $3.19 \pm 0.62$ & \\
\hline
\end{tabular}

SD: Standard deviation.

${ }^{*} p<0.05$.

\section{Discussion}

Numerous authors have strived to delineate the causes of academic failure and slumps among medical students $[9,10]$, but there is a marked paucity of studies to date that address AFT.

This present study revealed that AFT tendencies affects academic scores. Although the mean feeling scores for the improvement group were lower than those of the decline group, the mean scores for behavior and preference for difficult subjects were comparatively higher in the latter group.

We concluded that the improvement group experienced greater negative feelings after academic failure but that they also preferred more difficult subjects and putting in more effort in order to overcome their emotional difficulties and weaknesses. We also found that behavior factors and a preference for difficult subjects contributed significantly to establishing constructive actions after academic failure.

These observations and summaries are in contrast to previously reported results by other authors [11]. In some studies, students with low academic motivation were more prone to feeling negative emotions after academic failure, followed by inactivity or inability to overcome their difficulties [12,13]. However, we showed that whereas the improvement group students demonstrated more negative feelings after academic failure compared with those in the decline group, the former strived to overcome these situations by increasing their academic efforts and seeking more difficult and challenging subjects for study. These observations suggest that AFT significantly affects overcoming academic failures and enhancing academic scores.

Even though this study was confined to a single teaching institution and was limited to first- and secondyear medical students prior to their beginning clinical clerkship, the authors believe that we were able to show the tendencies of medical students in delicate academic situations. Furthermore, observations from our data may contribute to the supervision of those medical students who require motivation and heightened academic standards after they experience academic failure so that they may overcome their difficulties more smoothly. We further hope to prevent academic stress and formulate adequate supervision guidelines for medical students by investigating the relationship between AFT and efforts to overcome poor academic scores.

Careful scrutiny of not only the AFT of each individual medical student but also his or her emotional characteristics should be subject to adequate consideration and evaluation so that a positive, happy, and hopeful future will be provided during student super- 
vision by peers and faculty.

Acknowledgements: None.

Funding: None.

Conflicts of interest: None.

\section{References}

1. Chun KH, Song YM. The achievement goal orientation differences of medical students according to the academic failure tolerance and self-efficacy. Korean J Educ Res 2011; 49: 183-211.

2. Ten Cate TJ, Kusurkar RA, Williams GC. How selfdetermination theory can assist our understanding of the teaching and learning processes in medical education: AMEE guide No. 59. Med Teach 2011; 33: 961-973.

3. Simkin DK, Lederer JP, Seligman ME. Learned helplessness in groups. Behav Res Ther 1983; 21: 613622.

4. Clifford MM. How learning and liking are related: a clue. J Educ Psychol 1973; 64: 183-186.

5. Clifford E, Clifford M. Social and psychological problems associated with clefts: motivations for cleft palate treatment. Int Dent J 1986; 36: 115-119.

6. Deci EL, Ryan RM. Self-determination theory in health care and its relations to motivational interviewing: a few comments. Int J Behav Nutr Phys Act 2012; 9: 24.

7. Pintrich PR. An achievement goal theory perspective on issues in motivation terminology, theory, and research. Contemp Educ Psychol 2000; 25: 92-104.

8. Kim A, Clifford MM. Goal source, goal difficulty, and individual difference variables as predictors of responses to failure. British J Educ Psychol 1988; 58: 28-43.

9. Yune SJ, Park KH, Chung WJ, Lee SY. The effects of attribution tendencies, academic stress, and coping efficacy on academic adjustment of medical students. Korean J Med Educ 2011; 23: 167-174.

10. Yoo HH, Park KH. Relationships among emotional intelligence, ego-resilience, coping efficacy, and academic stress in medical students. Korean J Med Educ 2015; 27: 187-193.

11. Kim YB. Top ranked school students' coping of their academic underachievements and failure tolerance. Korean J Youth Stud 2011; 18: 31-47.

12. Kusurkar R, Kruitwagen C, ten Cate O, Croiset G. Effects of age, gender and educational background on strength of motivation for medical school. Adv Health Sci Educ Theory Pract 2010; 15: 303-313.

13. Wouters A, Bakker AH, van Wijk IJ, Croiset G, Kusurkar RA. A qualitative analysis of statements on motivation of applicants for medical school. BMC Med Educ 2014; 14: 200. 